\title{
What Is the Clinical Value of Lung Volumes?
}

\author{
Gregg L Ruppel MEd RRT RPFT FAARC
}

\author{
Introduction \\ Is a Low TLC (ie, Restriction) a Useful Measurement? \\ Do Lung Volumes Tell Us Anything Meaningful About Obstruction? \\ Does It Make Any Difference How You Measure Lung Volumes? \\ Summary
}

\begin{abstract}
Lung volumes are considered part of a complete pulmonary function test, but their value for enhancing clinical decision making is unknown. Unlike spirometry and diffusing capacity of the lung for carbon monoxide $\left(\mathrm{D}_{\mathrm{LCO}}\right)$, which do contribute to confirming or excluding a diagnosis, there are few clear indications when lung volumes are discriminatory. Confirming "restriction" when vital capacity (VC) or FVC is reduced is perhaps the most important. A restrictive pattern can have many etiologies, and clinicians often use VC or FVC as a primary index of lung volume. This makes "physiologic" sense because, in healthy subjects, and in patients with true restriction, VC comprises most of the total lung capacity (TLC). Mixed obstruction-restriction and the nonspecific pattern (ie, reduced FVC and $\mathrm{FEV}_{1}$, normal $\mathrm{FEV}_{1} / \mathrm{FVC}$ and TLC) require measuring TLC to confirm the underlying physiology. In obesity, $\mathrm{VC}$ and TLC may remain within normal limits, but functional residual capacity (FRC) can exponentially decrease. Increased lung volumes, particularly residual volume (RV), are commonly observed in airway obstruction. TLC may be normal, but is frequently increased in the late stages of COPD. Hyperinflation and air-trapping are terms commonly used to reflect these changes, but are not well standardized. The variability of lung volumes related to degree of obstruction suggests that measuring gas-trapping may be needed to monitor therapy. Changes in inspiratory capacity, RV, or FRC may be important gauges of response to bronchodilators or other hyperinflation-reducing therapies. How lung volumes are measured may be important, especially in patients who have moderate or severe airway obstruction. Body plethysmography is often considered more accurate than gas dilution methods in the presence of obstruction. However, the differences between techniques are not completely understood. Newer approaches such as computed tomography, although not suitable for routine testing, may help to delineate the true underlying physiology. Key words: pulmonary function; lung volumes. [Respir Care 2012;57(1): 26-35. (c) 2012 Daedalus Enterprises]
\end{abstract}

\section{Introduction}

The use of computer controlled pulmonary function equipment allows laboratories to perform an array of tests

\footnotetext{
Mr Ruppel is affiliated with the Department of Pulmonary, Critical Care, Sleep Medicine, and with the Pulmonary Function Laboratory, Saint Louis University Hospital, Saint Louis, Missouri.

Mr Ruppel presented a version of this paper at the 48th RESPIRATORY CARE Journal Conference, "Pulmonary Function Testing," held March 2527, 2011, in Tampa, Florida.
}

to investigate lung function in a repeatable and standardized manner. In addition to spirometry, measurements of diffusing capacity of the lung for carbon monoxide $\left(\mathrm{D}_{\mathrm{LCO}}\right)$

\footnotetext{
Mr Ruppel has disclosed relationships with Medical Graphics, Gilead Sciences, Biomedical Systems, and GlaxoSmithKline.

Correspondence: Gregg L Ruppel MEd RRT RPFT FAARC, Pulmonary Function Laboratory, Saint Louis University Hospital, 3635 Vista Avenue, St Louis MO 63104. E-mail: ruppelg1@slu.edu.
}

DOI: $10.4187 /$ respcare.01374 


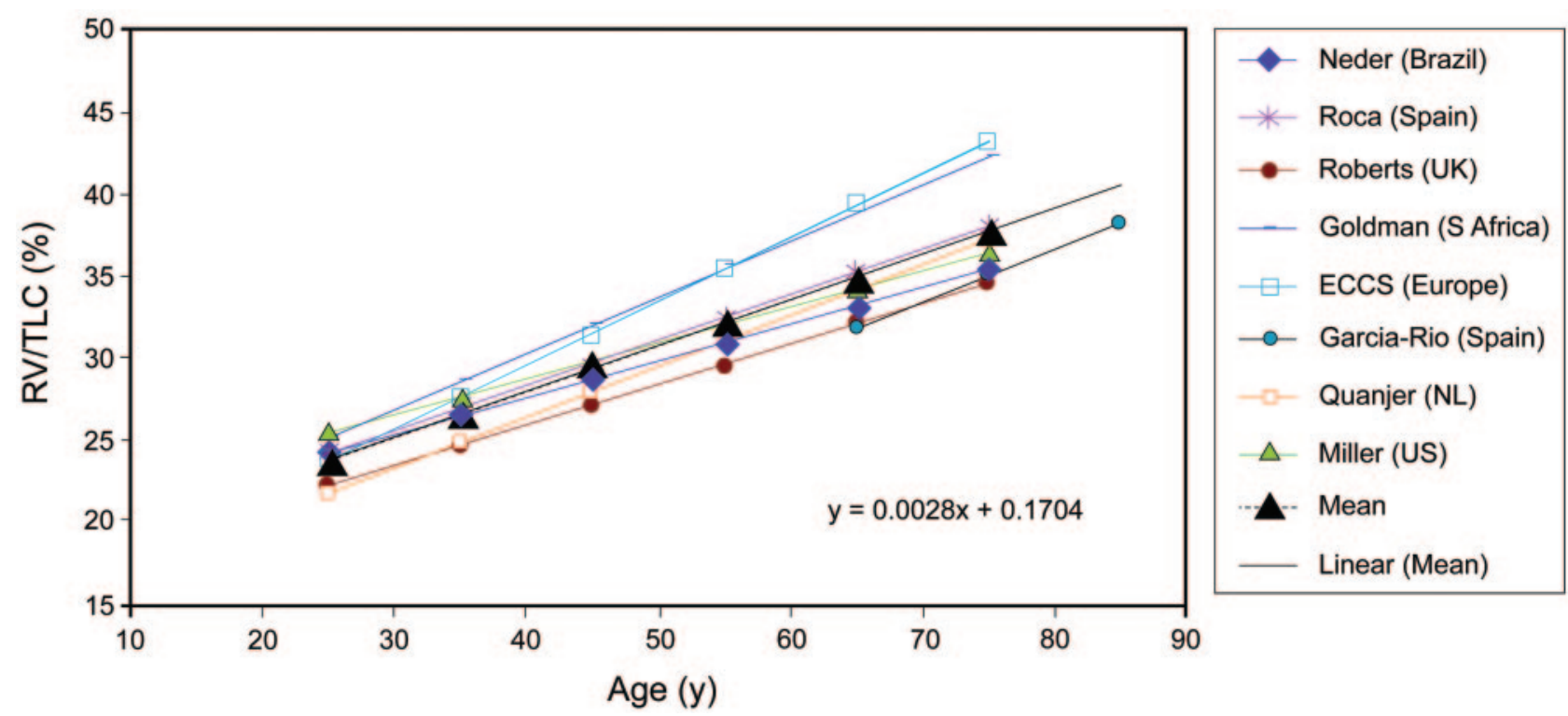

Fig. 1. Ratio of residual volume (RV) to total lung capacity (TLC), plotted as a function of age for authors of white predicted sets in which the ratio was reported. In each study, age is the main coefficient, describing the relationship between RV and TLC (see text).

and lung volumes have become de rigueur components of a "complete" pulmonary function test (PFT). Lung volumes in this context include measurements of total lung capacity (TLC) and its components, functional residual capacity (FRC) and residual volume (RV). None of these volumes can be measured directly by spirometry; each depends on measurement of the gas trapped in the lung after a maximal exhalation - the RV. Spirometry provides the vital capacity (VC) or FVC and its components, inspiratory capacity (IC) and expiratory reserve volume (ERV), but must be combined with other methods (plethysmography, gas dilution, or imaging) to estimate the trapped volume. While spirometry and $\mathrm{D}_{\mathrm{LCO}}$ each have a lengthy list of indications related to specific disease entities, the clinical indications for measurement of lung volumes are less well defined.

All the component tests of a complete PFT are measures of lung physiology. These tests are used to answer a specific clinical question (eg, why is the patient short of breath?), and the results of each should be considered as either supporting or negating the pre-test probability of a suspected diagnosis. ${ }^{1}$ Like cardiopulmonary exercise testing, lung volume measurements do not usually reveal a specific diagnosis when used to evaluate dyspnea at rest or during exertion. ${ }^{2}$ As is the case with exercise tests, lung volume measurements describe underlying physiologic patterns that should help to refine the differential diagnosis. In much of the literature, the concept of restriction is assessed solely using the $\mathrm{VC}$ or $\mathrm{FVC},{ }^{3}$ particularly when the etiology relates to chest wall abnormalities. This makes physiologic sense because the VC accounts for approximately $75 \%$ of the TLC in healthy young adults, with the proportion decreasing to around $60 \%$ in old age (Fig. 1). FVC is easily measured, and a low value is suggestive of a reduction in TLC as well. ${ }^{4}$ This relationship between FVC (VC) and TLC can be expressed as:

$$
\mathrm{TLC}=\mathrm{FVC}+\mathrm{RV}
$$

and considering that:

$$
1-(\mathrm{RV} / \mathrm{TLC})=(\mathrm{FVC} / \mathrm{TLC})
$$

TLC can be estimated:

$$
\mathrm{TLC}=\mathrm{FVC} /[1-(\mathrm{RV} / \mathrm{TLC})]
$$

This has practical applications in that a predicted TLC can be estimated from predicted FVC (VC), but is dependent on how well the predicted FVC fits the patient (age, height, ethnicity, etc), as well as the assumption that RV/ TLC ratio is solely a function of age. ${ }^{5}$

In many clinical situations, measurement of VC or FVC is all that may be required to assess a patient's lung function. ${ }^{6}$ This is particularly true when the subject's diagnosis has been established and pulmonary function testing is being used to track the progression of the disease or response to therapy. It is important to note that measurement of VC or FVC must be performed acceptably. Poorly performed spirometry, whether a forced or slow maneuver, will usually underestimate the true lung volume. ${ }^{7}$ Unlike many diagnostic procedures, spirometry and lung volume measurements require effort and cooperation on the part of the subject, along with attention to acceptability and 
Table 1. Clinical Conditions in Which Measurement of Lung Volumes May Be Indicated

\begin{tabular}{|c|c|c|c|}
\hline Clinical Condition & Lung Volume & Clinical Importance & First Author \\
\hline Asthma & TLC & $\begin{array}{l}\text { Restrictive impairment occurred in } 8 \% \text { of asthmatics, } \\
\text { without increase in FRC or RV }\end{array}$ & Miller $^{12}$ \\
\hline Interstitial lung disease & TLC & $\begin{array}{l}\text { Loss of TLC may be greater than loss of VC in } \\
\text { interstitial lung disease patients }\end{array}$ & Boros $^{13}$ \\
\hline Radiation and chemotherapy & TLC & $\begin{array}{l}\text { Chemo }+ \text { radiation exacerbates post-treatment decrease } \\
\text { in TLC and } D_{L C O}\end{array}$ & Gopal $^{14}$ \\
\hline Combined obstruction and restriction & TLC & $\begin{array}{l}\text { Severity of obstruction may be overestimated in patients } \\
\text { with combined obstruction/restriction. Combined } \\
\text { pattern occurs infrequently; clinicians overestimate its } \\
\text { prevalence }\end{array}$ & $\begin{array}{l}\text { Balfe }^{10} \\
\text { Gardner }^{15} \\
\text { Diaz-Guzman }^{16}\end{array}$ \\
\hline Obesity & FRC, TLC & $\begin{array}{l}\text { Reduced thoracic expansion and chest wall fat account } \\
\text { for restriction in some obese subjects }\end{array}$ & $\begin{array}{l}\text { Watson }^{17} \\
\text { Babb }^{18}\end{array}$ \\
\hline \multicolumn{4}{|c|}{$\begin{array}{l}\text { TLC }=\text { total lung capacity } \\
\text { FRC }=\text { functional residual capacity } \\
\text { RV }=\text { residual volume } \\
D_{\text {LCO }}=\text { diffusing capacity of the lung for carbon monoxide }\end{array}$} \\
\hline
\end{tabular}

repeatability judged by the testing personnel. In addition to the quality of the data obtained, reference values need to be carefully selected. ${ }^{1}$ Although validated reference sets are available for some groups (National Health and Nutrition Examination Survey III for whites, AfricanAmericans, and Mexican-Americans), there are other populations for whom healthy "normal" values are not widely available. VC and FVC are often expressed as percents of the predicted value. Percents of predicted introduce age and height bias. Using a fixed percentage, such as $80 \%$ of predicted, as the lower limit of normal (LLN) is inappropriate for judging if the FVC (or any other lung volume) is abnormally low. ${ }^{8}$

If the $\mathrm{VC}$ maneuver is properly performed and the result is below a statistically valid LLN, additional lung volume measurements may be indicated. A low FVC can be caused by either obstruction or restriction. In the former case, airway obstruction has already been diagnosed by pre- and post-bronchodilator spirometry. Measurement of lung volumes (ie, TLC) in the presence of obstruction will usually show a normal or increased volume. For patients with end-stage emphysema who are candidates for lungvolume reduction, or in the case of bullous emphysema, assessment of RV/TLC may be useful for planning therapy. ${ }^{9}$ Lung volumes measured plethysmographically may be compared to those made using dilutional techniques to estimate the volume of trapped gas (see last section of this review). Less commonly, airway obstruction and a restrictive process may co-exist so that TLC is reduced below the LLN in spite of the obstructive process. ${ }^{10}$ Some patients who present with symptoms of asthma may have a normal $\mathrm{FEV}_{1} / \mathrm{FVC}$ ratio but a decreased FVC or TLC, suggesting true restriction. ${ }^{11,12}$

If the FVC or VC is reduced and there is no evidence of obstruction, lung volumes may be indicated to determine whether the RV is also decreased (see next section). The causes of a restrictive pattern (reduced VC, RV and TLC) can be divided into three categories:

- Intrinsic (eg, interstitial lung disease, pneumonitis)

- Extrinsic (eg, kyphoscoliosis, cardiomegaly)

- Neuromuscular (eg, myasthenia, ALS)

A differential diagnosis based on the patient's history and physical findings, along with a chest $\mathrm{x}$-ray, may be sufficient to establish the cause of the reduced VC. Measurements of RV or TLC help to quantify the extent of the defect, but typically do not provide additional clinical information useful for therapeutic intervention. In cases where the therapy seeks to reverse pulmonary impairment, such as corrective surgery for kyphoscoliosis, lung volumes may be useful to document the improvement. There are a few clinical situations in which lung volumes are characteristically reduced and TLC may be more useful than VC or FVC alone (Table 1).

\section{Is a Low TLC (ie, Restriction) a Useful Measurement?}

Aaron and colleagues ${ }^{4}$ demonstrated what might be considered intuitive regarding the relationship between FVC, RV, and TLC. They evaluated 470 patients who had restriction (TLC $<5 \% \mathrm{CI}$ ) to assess whether a low FVC could be used to predict that restriction. When the FVC was within the normal range, the probability of a restrictive pattern was very low (2.4\%). If the FVC was reduced, the probability of a reduced RV (and hence a low TLC) was in the range of 50-60\%. In effect, a validly performed FVC excludes restriction if it is normal, but requires an additional evaluation if it is low. They also found that a 


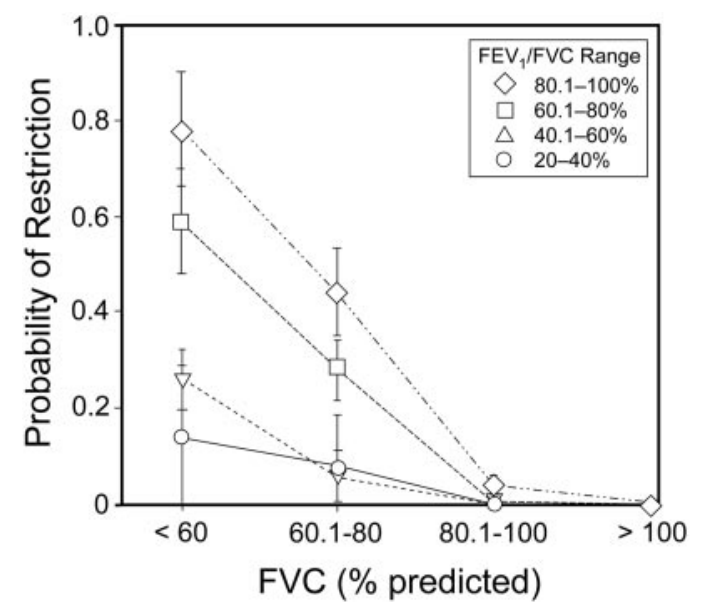

Fig. 2. Probability of restrictive lung disease plotted against FVC (percent of predicted) for a large population of subjects referred for pulmonary function tests. As FVC falls the likelihood of restriction increases, but only to about $50 \%$, and it differs depending on the degree of obstruction present. (From Reference 4, with permission.)

low FVC accompanied by evidence of obstruction (that is a low $\mathrm{FEV}_{1} / \mathrm{FVC}$ ratio) reduced the likelihood of restriction even further (Fig. 2).

The same group modeled and validated an algorithm to assist in decision making regarding when to perform lung volumes to diagnose restriction. ${ }^{19}$ Their model suggested that an $\mathrm{FVC}<85 \%$ of predicted and an $\mathrm{FEV}_{1} / \mathrm{FVC}>55 \%$ identified patients in whom lung volumes were needed to exclude restriction. This approach had a sensitivity of $96 \%$ and a negative predictive value of $98 \%$. Vandervoorde et $\mathrm{al}^{20}$ found similar results in a large cohort of patients using the $\mathrm{FEV}_{6}$ as a surrogate for $\mathrm{FVC}$, and $\mathrm{FEV}_{1} / \mathrm{FEV}_{6}$ as a surrogate for the standard ratio. A normal FVC or $\mathrm{FEV}_{6}$ almost always excludes a restrictive pattern. Unless there is evidence from the patient's history or physical examination suggesting restriction, measurement of TLC is not needed if the FVC is within normal limits. Restriction is also unlikely in the presence of moderate to severe obstruction.

Hyatt et $\mathrm{al}^{21}$ characterized a commonly observed pattern in which FVC and $\mathrm{FEV}_{1}$ are reduced, $\mathrm{FEV}_{1} / \mathrm{FVC}$ is normal or increased, and TLC is within normal limits; this combination has been termed the "nonspecific" pattern. In a sample of 100 patients with this pattern, two thirds had evidence of airways disease, while the remainder showed signs of thoracic restriction (eg, obesity, etc). The study investigators postulate a volume de-recruitment mechanism to explain the relationship between FVC, RV, and TLC in the subjects with airway involvement. In a follow-up study, Iyer et $\mathrm{al}^{22}$ looked at a larger cohort of patients with the nonspecific pattern who were tested on more than one occasion. They observed that the non-specific pattern persisted in $64 \%$ of the subjects, with equal numbers converting to either an obstructive or a restrictive pattern (15\% and 16\%, respectively). The overall prevalence of this nonspecific pattern is unknown but may be as high as $10-15 \%$. Accurate measurement of TLC (along with $\mathrm{FVC}$ and $\mathrm{VC}$ ) is required to make the diagnosis, but distinction between true restriction and the nonspecific pattern may be ascertained by clinical diagnosis as well. ${ }^{23}$

A reduced TLC can occur in patients with concomitant airway obstruction (ie, mixed obstruction and restriction). The prevalence of mixed obstruction-restriction is unknown but assumed to be an infrequent occurrence. Dykstra and colleagues $^{24}$ evaluated 4,774 patients with airway obstruction and found that only $9.5 \%$ of those with a reduced FVC also had a TLC below the LLN. In this study, patients who had mixed obstruction-restriction had a higher $\mathrm{FEV}_{1} / \mathrm{FVC}$ ratio and less severe obstruction. Balfe and co-workers ${ }^{10}$ looked at the possibility of overestimation of the degree of obstruction when there is co-existing restriction. $\mathrm{FEV}_{1} \%$ predicted is used almost universally to categorize the severity of obstruction. But because restrictive lung disease can reduce $\mathrm{FEV}_{1}$ along with FVC and TLC, the severity of obstruction may be less than in subjects who do not have a restrictive component. Balfe et al found this to be the case in a small cohort of patients and recommended grading severity of obstruction on the basis of their $\mathrm{FEV}_{1} / \mathrm{FVC}$. Recently, Gardner et al ${ }^{15}$ identified 199 patients from a large database who had combined obstruction and restriction. These investigators adjusted the $\mathrm{FEV}_{1} \%$ predicted by dividing it by the TLC \% predicted and found that three quarters of the patients moved into a less severe category of obstruction (using American Thoracic Society/European Respiratory Society [ATS/ERS] grading for COPD). Similar shifts were observed using asthma severity guidelines. They also noted that adjusted $\mathrm{FEV}_{1} \%$ predicted values correlated better with the observed RV/TLC ratios in these patients. Measurement of TLC is needed to identify mixed obstructive-restrictive patterns and may be useful for more accurately assessing the obstructive component.

Some older studies of lung volumes suggested that obesity resulted in a restrictive pattern. ${ }^{25}$ A recent investigation by Jones et al ${ }^{26}$ looked at lung volumes in 373 patients, across a range of body mass index (BMI) values. In this population increasing BMI was associated with a linear decline in both VC and TLC, but with few individual patients falling below the LLN for either parameter, even in those with morbid obesity. However, the study found an exponential decrease in FRC and ERV, with the steepest decline in those patients in $25-35 \mathrm{~kg} / \mathrm{m}^{2}$ BMI range (Fig. 3). Because airway resistance increases as FRC decreases, the authors speculate that increased shortness of breath may occur as BMI migrates from overweight into mild obesity. Leone and colleagues ${ }^{27}$ investigated the relationship between abdominal obesity and impaired lung function in a very large population residing in Paris. They found that the 

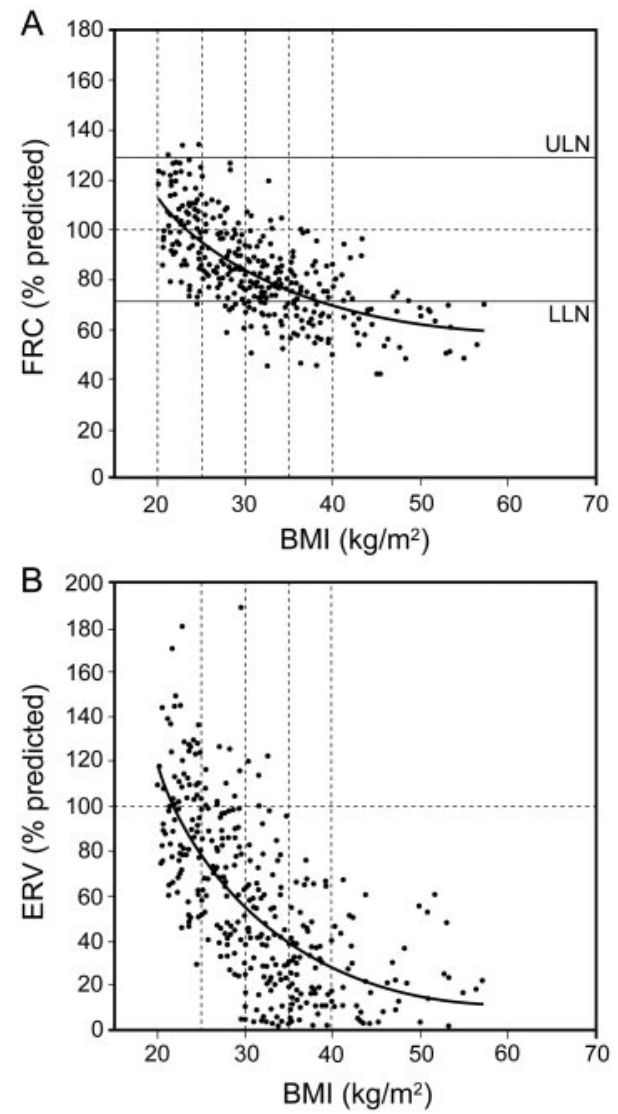

Fig. 3. Lung volume changes in obesity. Functional residual capacity (FRC) and expiratory reserve volume (ERV) \% predicted plotted versus body mass index (BMI) in 373 patients. Changes in each parameter are exponential (solid curved line), with the greatest change in the transition between overweight $\left(>25 \mathrm{~kg} / \mathrm{m}^{2}\right)$ and obese $\left(>30 \mathrm{~kg} / \mathrm{m}^{2}\right)$. (From Reference 26, with permission.)

larger the waist size, the lower the FVC, even in subjects whose overall weight was normal. This degree of abdominal obesity has become commonplace in the United States and is associated with increased risk of death from cardiovascular disease or cancer. ${ }^{28}$ Some clinicians regard these spirometric findings as evidence of restriction, without measurement of TLC or FRC. As was observed in the study by Jones and Nzekwu, ${ }^{26}$ VC can be significantly reduced but still within normal limits. Spirometry alone may not be able to answer the question, "Is the patient's shortness of breath due to obesity?"

\section{Do Lung Volumes Tell Us Anything Meaningful About Obstruction?}

The terms "air-trapping" and "hyperinflation" are frequently used in the interpretation of PFTs, although there are no widely accepted definitions for either. These descriptors are usually taken to mean that there are alterations in the normal configuration of lung volume compart- ments. The RV is increased, both in its absolute volume and in relation to the VC, the TLC, or both. ${ }^{29}$ Two presentations of increased RV are commonly observed: one in which RV increases at the expense of the VC, with TLC remaining within normal limits, or a second scenario in which RV increases but with a preserved VC, resulting in an increased TLC. ${ }^{30}$ It is unclear how best to describe these changes, but ratios such as the RV/TLC expressed as a percentage have been widely adopted. Many laboratories use a percent of predicted with fixed cutoffs (ie, 80-120\%) to assess increases or decreases in lung volumes. Quanjer, in unpublished data (Phillip H Quanjer, on behalf of the Pulmonaria Group, personal communication, 2011), computed the upper limit of normal (ULN) for RV, using anthropometric data (age, height, sex) from the National Health and Nutrition Examination Survey III population and the lung volume equations promulgated by the European Community for Coal and Steel. ${ }^{31}$ The value for the upper 5th percentile for each subject was expressed as a percentage of the predicted value. As shown in Figure 4 (for white subjects) the upper limit of normal for RV is in the range of $140-150 \%$ of predicted in young subjects, and decreases to $125-135 \%$ in elderly subjects. These data suggest that RV is quite variable in healthy subjects, and that the widely used fixed criterion of $120 \%$ may result in an overestimation of gas trapping.

Dykstra and colleagues ${ }^{24}$ evaluated TLC, RV, and the $\mathrm{RV} / \mathrm{TLC}$ ratio in a large group of patients with airway obstruction to see whether lung volumes could discriminate between asthma and COPD. They found that RV and RV/TLC were more sensitive than TLC to the degree of airway obstruction. As airway obstruction (gauged by the $\mathrm{FEV}_{1} \%$ predicted) falls from mild to moderate $(\sim 50 \%)$, $\mathrm{RV}$ increases while TLC tends to remain the same. In general, lung volumes are not able to distinguish whether the increases are caused by COPD versus asthma, particularly when the diseases have progressed to moderate or severe airway obstruction. However, as shown in Figure 5, there is a great deal of variability in RV/TLC, particularly around the LLN for $\mathrm{FEV}_{1}$. Although RV or RV/TLC may not help make a diagnosis as to whether the patient has asthma or COPD, it may be important to know how much "hyperinflation" is present if reducing it is a therapeutic goal. 32,33

There has been substantial interest in the IC as an index of hyperinflation. ${ }^{34,35}$ FRC typically increases as airway obstruction worsens; this frequently results in a reduction in IC, while TLC does not change significantly. For this reason, IC, which can be measured by spirometry, may be a useful way to assess lung volumes without actually measuring FRC or RV. Casanova et $\mathrm{al}^{36}$ used the ratio of $\mathrm{IC} / \mathrm{TLC}$ as one such indicator and related it to survival in a population of patients with COPD. They observed significantly increased respiratory and overall mortality when 

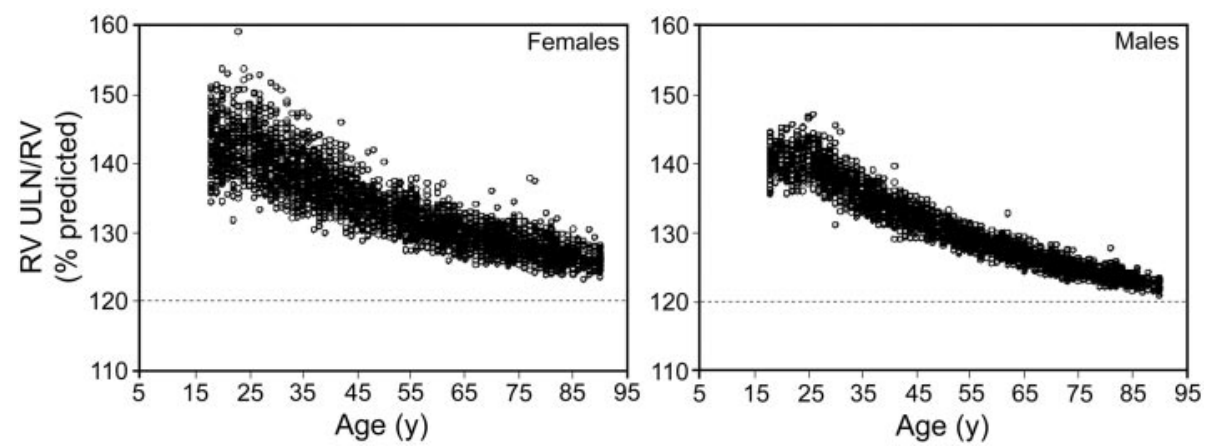

Fig. 4. Residual volume (RV) upper limit of normal plotted as a percentage of the predicted value. Height and age of white subjects enrolled in the National Health and Nutrition Examination Survey III study were used to calculate the predicted RV and its upper limit of normal, using the European Community for Coal and Steel equations. All values fall above $120 \%$ of predicted, a value frequently used as the upper limit of normal when assessing air-trapping. (Unpublished data from Phillip H Quanjer, used with permission.)

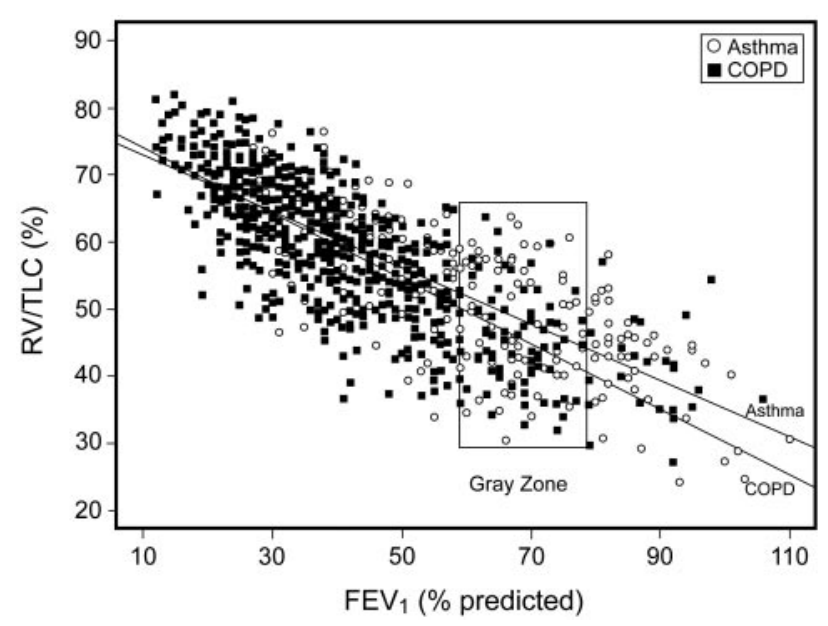

Fig. 5. Residual volume (RV) to total lung capacity (TLC) ratio versus $\mathrm{FEV}_{1} \%$ predicted. RV/TLC, expressed as a percent, is plotted against the \% predicted $\mathrm{FEV}_{1}$ for 4,774 patients with asthma or COPD, with solid lines representing the best fit for each. The shaded area or gray zone represents the large degree of variability for subjects near the lower limit of normal for the FEV ${ }_{1}$. (From Reference 24, with permission.)

the IC/TLC fell to less than $25 \%$. In addition to serving as an index for survival, IC has also emerged as a useful tool for assessing changes in gas trapping for various therapies. For example, Van Noord and co-workers ${ }^{37}$ measured IC over a 24 hour epoch to evaluate reduction in air trapping following treatment with different combinations of bronchodilators. This study recorded acute improvement in IC, which exceeded that of the $\mathrm{FEV}_{1}$, as well as a larger average increment in IC over the 24-hour period (215 vs $198 \mathrm{~mL}$ ). Multiple reports from O'Donnell and colleagues ${ }^{34,38}$ have demonstrated that air-trapping, whether measured by FRC or estimated from IC, is closely related to the sensation of dyspnea and to exercise limitation in patients who have COPD. A recent study from this group looked at bronchodilator response as gauged by spiro- metric $\left(\mathrm{FVC}, \mathrm{FEV}_{1}, \mathrm{IC}\right)$ and lung volume (FRC, RV, TLC) parameters. ${ }^{39}$ Notably, they found an increased RV in mild, moderate, and severe obstruction. They also observed that the largest change in percent of predicted following bronchodilator and the frequency of a positive response was greatest for RV (Fig. 6). Barisione and co-workers ${ }^{40}$ reported a decrease in hyperinflation in a small group of subjects experiencing the bronchiolitis obliterans syndrome after hematopoietic stem cell transplantation. They observed an increase in partial flow volume curves that corresponded with a decrease in $\mathrm{FRC}$, even though $\mathrm{FEV}_{1}$ and FVC did not change. The data from these studies suggest that air-trapping and hyperinflation, and the variables that quantify them, may be important for treating those who have obstruction. IC is a convenient tool for making these types of assessments, but RV may present the best way to evaluate therapies aimed at reducing air-trapping. ${ }^{41}$

\section{Does It Make Any Difference How You Measure Lung Volumes?}

In 2005 a joint committee of the ATS/ERS published the first comprehensive guidelines for performance of lung volumes. ${ }^{6}$ Included in these were recommendations for performance of plethysmographic and gas dilution lung volumes. No one methodology was promoted over the others, but the advantages and disadvantages of each were laid out, along with "best practices," as judged by the committee. Body plethysmography was recognized as a technique that overcomes problems of maldistribution of gas within the lung, but at the same time could overestimate lung volumes unless the subject was coached to pant at frequencies $<1 \mathrm{~Hz}^{42}$ The guidelines also recognized that dilutional techniques (ie, He dilution or $\mathrm{N}_{2}$ washout) could underestimate lung volume in patients who have airway obstruction. Because each of these techniques measures FRC, linked slow VC maneuvers were recommended 

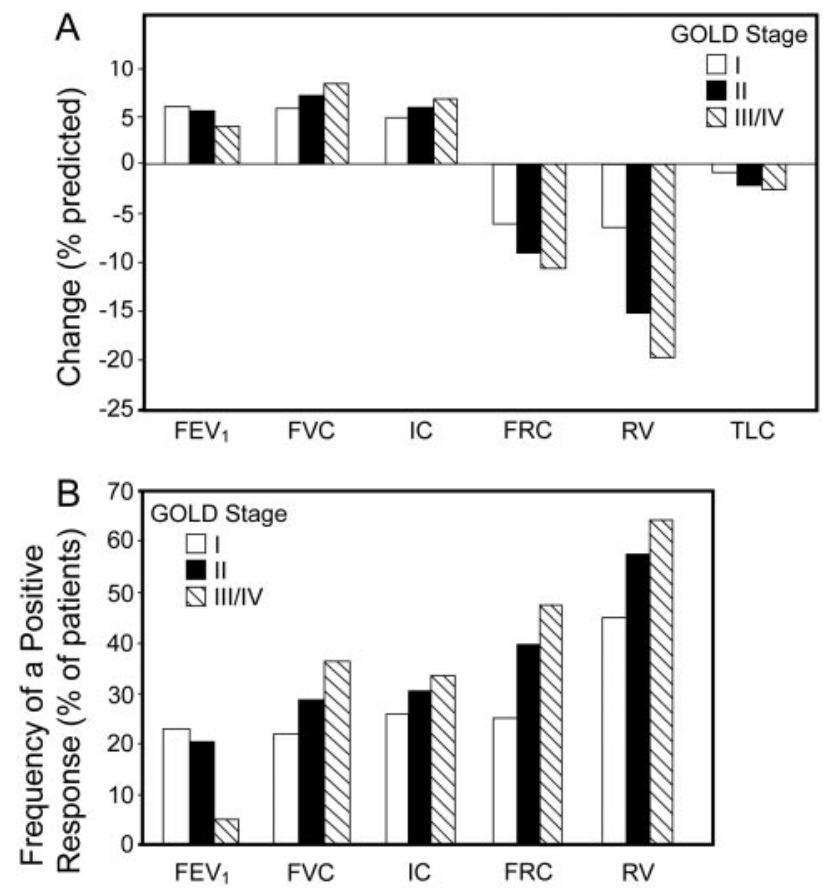

Fig. 6. A: Changes in percent of predicted following bronchodilator for spirometric and lung volumes variables. B: Frequency of a positive bronchodilator response $(10 \%$ or greater change from baseline) in patients with COPD. RV showed the largest change and had the greatest frequency of positive responses. GOLD = Global Initiative for Chronic Obstructive Lung Disease. IC = inspiratory capacity. FRC = functional residual capacity. RV $=$ residual volume. TLC = total lung capacity. (From Reference 39, with permission.)

for the calculation of RV and TLC. The guidelines note that imaging techniques (computed tomography [CT], chest roentgenogram, etc) compare favorably with plethysmography and gas dilution. However, imaging technologies require the patient to breath-hold at or near TLC, may expose the patient to excessive radiation, and tend to be prohibitively expensive for routine measurements.

Plethysmographic overestimation of thoracic gas volume $\left(\mathrm{V}_{\mathrm{TG}}\right)$ in patients with moderate or severe obstruction was pointed out almost 30 years ago by Rodenstein and Stanescu ${ }^{43}$ and Shore et al. ${ }^{44}$ This was demonstrated by measuring esophageal pressure during plethysmographic maneuvers and comparing it to the conventional mouth pressure signal. In healthy subjects these 2 signals are quite similar, both reflecting changes in alveolar pressure. In obstructed patients, mouth pressure may not equal alveolar pressure for any of several reasons, and true alveolar pressure changes are usually underestimated. There may also be a significant phase shift between mouth and box pressures. As a result, the slope of the line that defines the relationship between mouth pressure and box pressure is spuriously reduced and $\mathrm{V}_{\mathrm{TG}}$ is overestimated. Fortunately, these phenomena are frequency dependent; the
Table 2. Comparison of Mean Differences in Lung Volumes in Patients With Airway Obstruction*

\begin{tabular}{lcc}
\hline \hline \multicolumn{1}{c}{ Volume Comparison } & $\begin{array}{c}\text { Mean } \\
\text { Difference (L) }\end{array}$ & $P$ \\
\hline Plethysmography versus helium dilution & 0.93 & $<.001$ \\
Plethysmography versus CT & 1.07 & $<.001$ \\
Helium dilution versus CT & 0.15 & .82 \\
& & \\
* Post hoc comparison (Scheffé). & & \\
CT = computed tomography & & \\
(Adapted from Reference 45.) & & \\
\end{tabular}

magnitude of the error increases as panting frequencies rise above $1 \mathrm{~Hz}$. To minimize overestimation of $\mathrm{V}_{\mathrm{TG}}$ in obstructed patients, coach them to pant slowly at, 0.5 to $1.0 \mathrm{~Hz}$.

A recent study by O'Donnell and colleagues ${ }^{45}$ resurrected the discussion regarding overestimation of lung volumes by the plethysmographic method. These investigators looked at 132 patients in 3 centers and compared lung volumes measured by body plethysmography, He dilution, and CT. Standardized methodology was used for each lung volume technique. Significant differences were observed between plethysmography and either CT or He dilution, but not between $\mathrm{CT}$ and He dilution. In subjects with obstruction the mean differences between body plethysmograph and the other 2 techniques were approximately $1 \mathrm{~L}$ (Table 2). The largest differences $(>1 \mathrm{~L})$ were usually in patients with very severe obstruction $\left(\mathrm{FEV}_{1}<30 \%\right.$ predicted). These results suggest that perhaps plethysmography, even if performed properly, may overestimate lung volumes in severely obstructed patients. It is noteworthy that this paper generated a substantial volume of responses. ${ }^{46,47}$ Most of these pointed out basic differences in the methodologies (eg, CT performed supine, breathholding at TLC, etc). Milite et $\mathrm{al}^{48}$ examined differences between single- and multiple-breath dilutional techniques and body plethysmograph in 55 patients with emphysema. In their comparison of He dilution and plethysmographic lung volumes they observed a mean difference of approximately $500 \mathrm{~mL}$, which appeared to be unrelated to the severity of obstruction ( $P$ for interaction $=.25$ ). This study also confirmed what has been demonstrated repeatedly, that lung volumes measured by single-breath dilution are significantly lower than either multiple-breath dilution or plethysmographic volumes ${ }^{49,50}$ (Fig. 7). When lung volumes are used to make therapeutic/clinical decisions, the method by which those volumes are derived may need to be considered. ${ }^{32,51}$

CT scanning provides an option to body plethysmography or gas dilution for measuring lung volumes. ${ }^{52}$ However, it is more expensive than any of the conventional methods. It also requires the subject to breath-hold at or 


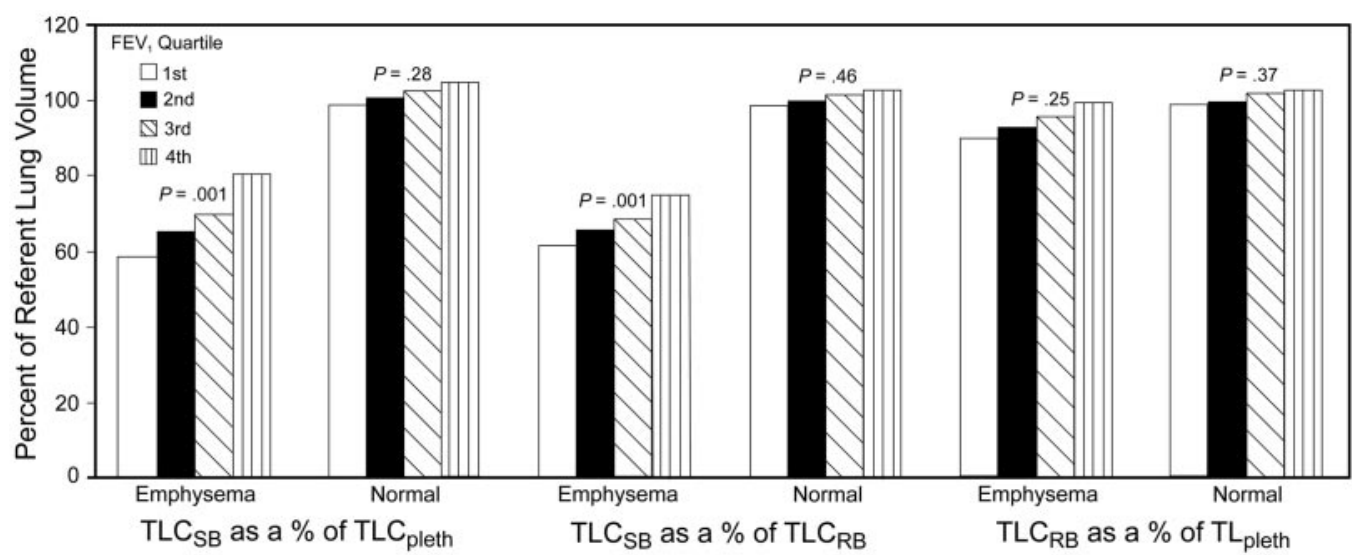

Fig. 7. Comparison of total lung capacity (TLC) measured by single-breath (SB) gas dilution, rebreathing (RB) gas dilution, and plethysmography (pleth) as the reference in normal subjects and patients with emphysema. Bars represent quartiles of $\mathrm{FEV}_{1} \%$ predicted as an index of obstruction: quartile $1=$ lowest quartile for $\mathrm{FEV}_{1} \% . P$ values represent the interaction between $\mathrm{FEV}_{1} \%$ (as a continuous measure) and the respective lung volume. $P$ values $<.05$ indicate that lung volume agreement varies with the degree of obstruction $\left(\mathrm{FEV}_{1} \%\right)$. $\mathrm{TLC}_{\mathrm{SB}}$ significantly underestimates lung volume when compared to either RB or pleth. TLC $\mathrm{RB}_{\mathrm{RB}}$ does not show significant interaction with $\mathrm{FEV}_{1} \%$ in the patients with emphysema, suggesting that the rebreathing technique is minimally affected by airway obstruction. (From Reference 48 , with permission.)

near TLC, which may be difficult for many patients. ${ }^{53}$ Although spirometry can be used to verify that the patient inspired to near TLC, this is not done routinely. A recent review of low dose ionizing radiation from procedures done after myocardial infarction suggests that there is an increased risk of cancer as result of these procedures. ${ }^{54} \mathrm{CT}$ of the chest typically gives a lower dose than myocardial perfusion imaging (7 vs 15.6 milli-Sieverts), but is similar to that of a cardiac catheterization or CT of the abdomen. ${ }^{55}$ If a patient needs a chest $\mathrm{CT}$ for diagnostic purposes, calculation of lung volume may be a useful adjunct.

\section{Summary}

Lung volumes do not provide much additional information for clinical decision making in most patients. An estimate of TLC may be required to resolve whether proportionately reduced $\mathrm{FVC}$ and $\mathrm{FEV}_{1}$ are caused by obstruction or restriction. TLC is indicated only if it assists in confirming or rejecting a diagnosis, or if it is needed for planning a course of therapy. Clinicians should ask the question, "What will I do with the result of the lung volume measurement?"

Because the FVC (or VC) comprises most of the TLC in healthy subjects and in those with pure restrictive disorders, a valid measurement of FVC provides valuable information about the lung volumes in general. Many patients present with a nonspecific ventilatory pattern in which $\mathrm{FVC}$ and $\mathrm{FEV}_{1}$ are reduced, but $\mathrm{FEV}_{1} / \mathrm{FVC}$ is normal or supra-normal. The other feature of the nonspecific pattern is a normal TLC. In order to confirm this pattern, an estimate of TLC is needed. Current evidence suggests that the nonspecific pattern may be associated with airway obstruction or obesity, but a majority of these patients do not convert to a conventional obstructive or restrictive pattern. Mixed obstructive-restrictive patterns are not common but may occur in about $10 \%$ of patients referred for PFTs. Measurement of TLC (\% predicted) can be used to adjust the $\mathrm{FEV}_{1} \%$ predicted to better categorize the degree of obstruction in patients who have mixed disease. Obesity is frequently assumed to cause restriction, but it appears that the most significant reductions occur, not in TLC or VC, but in FRC and ERV. These reductions tend to be exponential, with the most significant changes in those who are just overweight or mildly obese.

The usefulness of lung volumes is largely dependent on whether or not we need to know how large the RV is. RV appears to be quite variable in healthy subjects, and the upper limit of normal is probably significantly greater than $120 \%$ of predicted. It is clear that RV, TLC, and the RV/ TLC ratio all increase as airway obstruction worsens, but none of these measures does very well at distinguishing between asthma, COPD, or other causes of obstruction. But the variability of RV when the FEV ${ }_{1}$ is near its LLN may be reason enough to measure it if the result can assist in making therapeutic decisions. IC also reveals a lot about air-trapping because it reflects the end-expiratory level (ie, the FRC). Measuring IC requires only a spirometer; hence, it has demonstrated usefulness for quantifying increases in air-trapping during exercise as well as for decreases resulting from bronchodilator therapy. The prognosis for patients with airway obstruction, however, requires that the IC be related to the TLC (ie, IC/TLC ratio). Lastly, there is some evidence that changes in RV may be better 
than changes in FVC, FEV ${ }_{1}$, IC, or TLC to account for an individual patient's response to bronchodilator, particularly in advanced obstruction.

There are currently multiple methods for measuring lung volumes, including body plethysmography, single- and multiple-breath gas dilution, and imaging techniques such as CT scanning. The most recent ATS/ERS guidelines wisely refrained from advocating any one method over the others. Plethysmography, although sometimes considered the gold standard, can overestimate lung volumes in obstruction. Multiple-breath dilution techniques, long considered sub-optimal in patients with obstruction, may better represent the "true" lung volume than previously thought. Single-breath dilution techniques do progressively underestimate lung volumes as airway obstruction worsens. But this underestimation itself can be used as an index of ventilatory inhomogeneity within the lung. Although CT scanning offers an accurate alternative to the conventional methods, it is generally more expensive than traditional lung volume measurements. Technical problems such as prolonged breath-holding, and exposure to significant levels of ionizing radiation further limit its usefulness.

\section{REFERENCES}

1. Pellegrino R, Viegi G, Brusasco V, Crapo RO, Burgos F, Casaburi $\mathrm{R}$, Coates A, et al. Interpretative strategies for lung function tests. Eur Respir J 2005;26(5):948-968.

2. ERS Task Force; Palange P, Ward SA, Carlsen KH, Casaburi R, Gallagher CG, Gosselink R, O'Donnell DE, et al. Recommendations on the use of exercise testing in clinical practice. Eur Respir J 2007; 29(1):185-209.

3. Venkateshiah SB, Ioachimescu OC, McCarthy K, Stoller JK. The utility of spirometry in diagnosing pulmonary restriction. Lung 2008; 186(1):19-25.

4. Aaron SA, Dales RE, Cardinal P. How accurate is spirometry at predicting restrictive pulmonary impairment? Chest 1999;115(3): 869-873.

5. Miller WF, Scacci R, Gast LR. Laboratory evaluation of pulmonary function. Philadelphia: Lippincott; 1987:94-98.

6. Swanney MP, Beckert LE, Frampton CM, Wallace LA, Jensen RL, Crapo RO. Validity of the American Thoracic Society and other spirometric algorithms using FVC and forced expiratory volume at 6 s for predicting a reduced total lung capacity. Chest 2004;126(6): 1861-1866.

7. Wanger J, Clausen JL, Coates A, Pedersen OF, Bursasco V, Burgos F, et al. Standardisation of the measurement of lung volumes. Eur Respir J 2005(3):26:511-522.

8. Miller MR, Quanjer PH, Swanney MP, Ruppel G, Enright P. Interpreting lung function data using $80 \%$ predicted and fixed thresholds misclassifies more than 20\% of patients. Chest 2011;139(1):52-59.

9. Washko GR, Martinez FJ, Hoffman EA, Loring SH, Estépar RS, Diaz AA, et al; NETT Research Group. Physiological and computed tomographic predictors of outcome from lung volume reduction surgery. Am J Respir Crit Care Med 2010;181(5):494-500.

10. Balfe DL, Lewis M, Mohsenifar Z. Grading the severity of obstruction in the presence of a restrictive ventilatory defect. Chest 2002; 122(4):1365-1369.

11. Rothe T. True restrictive ventilatory pattern in asthma. J Asthma 2010;47(5):594-596.
12. Miller A, Palecki A. Restrictive impairment in patients with asthma. Respir Med 2007;101(2):272-276.

13. Boros PW, Franczuk M, Wesolowski S. Value of spirometry in detecting volume restriction in interstitial lung disease. Respiration 2004;71(4):374-379.

14. Gopal R, Starkschall G. Tucker SL, Cox JD, Liao Z, Hanus M, et al. Effects of radiotherapy and chemotherapy on lung function in patients with non-small-cell lung cancer. Int J Radiat Oncol Biol Phys 2003;56(1):114-120.

15. Gardner ZS, Ruppel GL, Kaminsky DA. Grading the severity of obstruction in mixed obstructive-restrictive lung disease. Chest 2011; 140(3):598-603.

16. Diaz-Guzman E, McCarthy K, Siu A, Stoller JK. Frequency and causes of combined obstruction and restriction identified in pulmonary function tests in adults. Respir Care 2010;55(3)310-316.

17. Watson RA, Pride NB, Thomas EL, Fitzpatrick J, Durighel G, McCarthy J, et al. Reduction of total lung capacity in obese men: comparison of total intrathoracic and gas volumes. J Appl Physiol 2010; 108(6):1605-1612.

18. Babb TG, Wyrick BL, DeLorey DS, Chase PJ, Feng MY. Fat distribution and end-expiratory lung volume in lean and obese men and women. Chest 2008;134(4):704-711.

19. Glady CA, Aaron SD, Lunau M, Clinch J, Dales RE. A spirometrybased algorithm to direct lung function testing in the pulmonary function laboratory. Chest 2003;123(6):1939-1946.

20. Vandevoorde J, Verbanck S, Schuermans D, Broekaert L, Devroey D, Kartounian J, Vincken W. Forced vital capacity and forced expiratory volume in six seconds as predictors of reduced total lung capacity. Eur Respir J 2008;31(2):391-395.

21. Hyatt RE, Cowl CT, Bjoraker JA, Scanlon PD. Conditions associated with an abnormal nonspecific pattern of pulmonary function tests. Chest 2009;135(2):419-424.

22. Iyer VN, Schroeder DR, Parker KO, Hyatt RE, Scanlon PD. The 'nonspecific' pulmonary function test: longitudinal follow-up and outcomes. Chest 2011;139(4):878-886.

23. D'Aquino LC, Rodrigues SC, deBarros JA, Rubin AS, Rosário Filho NA, Pereira CA. Predicting reduced TLC in patients with low FVC and a normal or elevated $\mathrm{FEV}_{1} / \mathrm{FVC}$ ratio. J Bras Pneumol 2010; 34(4):460-467.

24. Dykstra BJ, Scanlon PD, Kester MM, Beck KC, Enright PL. Lung volumes in 4,774 patients with obstructive lung disease. Chest 1999; 115(1):68-74.

25. Sugerman HJ. Pulmonary function in morbid obesity. Gastroenterol Clin North Am 1987;16(2):225-237.

26. Jones RL, Nzekwu MM. The effects of body mass index on lung volumes. Chest 2006;130(3):827-833.

27. Leone N, Courbon D, Thomas F, Bean K, Jégo B, Laynaert B, Guize L, Zureik M. Lung function impairment and metabolic syndrome: the critical role of abdominal obesity. Am J Respir Crit Care Med 2009;179(6):509-516.

28. Zhang C, Rexrode KM, van Dam RM, Li Ty, Hu FB. Abdominal obesity and the risk of all-cause, cardiovascular, and cancer mortality: sixteen years of follow-up in US women. Circulation 2008; 117(13):1658-1667.

29. Hughes JMB. Physiology and practice of pulmonary function. London: Association for Respiratory Technology and Physiology; 2009: 45-50.

30. Wanger J. Lung volumes and gas distribution tests. In: Ruppel GL. Manual of pulmonary function testing, 9th edition. St. Louis: Mosby Elsevier; 2008:90-116.

31. Quanjer PH, Tammeling GJ, Cotes JE, Pedersen OF, Peslin R, Yernault JC. Lung volumes and forced expiratory flows. Report of the Working Party Standardization of Lung Function Tests; European 
Community for Steel and Coal; Official Statement of the European Respiratory Society. Eur Respir J 1993;16(Suppl):5-40.

32. Tantucci C, Guerini M, Boni E, Corda L, Pini L. Tidal airway closure during bronchoconstriction in asthma: usefulness of lung volume measurements. J Asthma 2011;48(1):33-40.

33. Pelligrino R, Brusasco V. On the causes of lung hyperinflation during bronchoconstriction. Eur Respir J 1997;10(2):468-475.

34. Newton MF, O'Donnell DE, Forkert L. Response of lung volumes to inhaled salbutamol in a large population of patients with severe hyperinflation. Chest 2002;121(4):1042-1050.

35. O'Donnell DE, Forkert L, Webb KA. Evaluation of bronchodilator responses in patients with "irreversible" emphysema. Eur Respir J 2001;18(6):914-920.

36. Casanova C, Cote C, de Torres JP, Aguirre-Jaime A, Marin JM, Pinto-Plata V, Celli BR. Inspiratory-to-total lung capacity ratio predicts mortality in patients with chronic obstructive pulmonary disease. Am J Respir Crit Care Med 2005;171(6):591-597.

37. Van Noord JA, Aumann JL, Janssens E, Verhaert J, Smeets JJ, Mueller A, Cornelissen PJ. Effects of tiotropium with and without formoterol on airflow obstruction and resting hyperinflation in patients with COPD. Chest 2006;129(3):509-517.

38. O'Donnell DE, D'Arsigny C, Fitzpatrick M, Webb KA. Exercise hypercapnia in advanced chronic obstructive pulmonary disease: the role of lung hyperinflation. Am J Respir Crit Care Med 2002;166(5): 663-668.

39. Deesomchok A, Webb KA, Forkert L, Lam YM, Ofir D, Jensen D, O'Donnell DE. Lung hyperinflation and its reversibility in patients with airway obstruction of varying severity. COPD 2010;7(6): 428-437.

40. Barisione G, Bacigalupo A, Crimi E, Brusasco V. Acute bronchodilator responsiveness in bronchiolitis obliterans syndrome following hematopoietic stem cell transplantation. Chest 2011;139(3): 633-639.

41. Man WD, Mustfa N, Nikoletou D, Kaul S, Rafferty GF, Donaldson $\mathrm{N}$, et al. Effect of salmeterol on respiratory muscle activity during exercise in poorly reversible COPD. Thorax 2004;59(6):471-476.

42. Coates AL, Peslin R, Rodenstein D, Stocks J. Measurement of lung volumes by plethysmography. Eur Respir J 1997;10(6):2174-2185.

43. Rodenstein D, Stanescu D. Frequency dependence of plethysmographic volume in healthy and asthmatic patients. J Appl Physiol 1983;54(1):159-165.
44. Shore SA, Huk O, Mannix S, Martin JG. Effect of panting frequency on the plethysmographic determination of thoracic gas volume in chronic obstructive pulmonary disease. Am Rev Respir Dis 1983; 128(1):54-59.

45. O’Donnell CR, Bankier AA, Stielbellehner L, Reilly JJ, Brown R, Loring SH. Comparison of plethysmographic and helium dilution lung volumes: which is best in COPD? Chest 2010;137(5):1108-1115.

46. Stanescu D. How to measure lung volume? (letter). Chest 2010; 138(5):1280-1281.

47. Tantucci C. Comparison among different methods on measurement of total lung capacity in COPD (letter). Chest 2010;138(2): 458-459.

48. Milite F, Lederer DJ, Weingarten JA, Fani P, Mooney AM, Basner RC. Quantification of single-breath underestimation of lung volumes in emphysema. Respir Physiol Neurobiol 2009;165(2-3):215-220.

49. Punjabi NM, Shade D, Wise RA. Correction of single breath helium lung volumes in patients with airflow obstruction. Chest 1998;114(3): 907-918.

50. Roberts CM, MacRae KD, Seed WA. Multi-breath and single breath helium dilution lung volumes as a test of airway obstruction. Eur Respir J 1990;3(5):515-520.

51. Cazzola M, Rogliani P, Curradi G, Segreti A, Ciaprini C, Pezzuto G, Saltini C. A pilot comparison of helium dilution and plethysmographic lung volumes to assess the impact of a long-acting bronchodilator on lung hyperinflation in COPD. Pulm Pharmacol Ther 2009; 22(6):522-525.

52. Washko GR, Criner GJ, Mohsenifar Z, Sciurba FC, Sharafkhaneh A, Make BJ, et al. Computed tomographic-based quantification of emphysema and correlation to pulmonary function and mechanics. COPD 2008;5(3):177-186.

53. Bankier AA, O'Donnell CR, Boiselle PM. Respiratory instructions for CT examinations of the lungs: a hands-on approach. Radiographics 2008;28(4):919-931.

54. Eisenberg MJ, Afilalo J, Lawler PR, Abrahamowicz M, et al: Cancer risk related to low-dose ionizing radiation from cardiac imaging in patients after acute myocardial infarction. CMAJ 2011;183(4): 430-436.

55. Fazel R, Krumholz HM, Wang Y, Ross JS, Chen J, Ting HH, et al. Exposure to low-dose ionizing radiation from medical imaging procedures. N Engl J Med 2009;361(19):849-857.

\section{Discussion}

Culver: With regard to the variability of the RV, the RV may vary a lot among normal individuals, but, as you said in the conclusion, the RV measurement itself is certainly variable. Some of that is just mathematical; we measure an FRC, we add and subtract other increments, all those errors get added and then the sum gets divided by a denominator that's 1.5 to 2 liters and it becomes a large percent error. With 3 different 150-milliliter errors when you make those measurements, it can end up with $25 \%$ variability just in the mathematics, superimposed on whatever human variability there is. We often see that when there is an error in the plethysmographic measurement and you end up with TLC that's $80 \%$ and an FRC that's $70 \%$ and the RV is $20 \%$ and you say,"How could that happen?" Just because that same absolute error has been applied to each subdivision and it looks biggest when it's applied to the smallest one.

Ruppel: I agree with that, and I think the current guideline that recommends averaging IC and using that along with a mean measurement of FRC is probably a good approach. It can be prob- lematic, depending on who makes the measurements and who decides how to average the values. It is an issue that we deal with on a day-to-day basis.

Culver: In big studies RV has been shown to be quite a subtle and sensitive indicator of early airway obstruction, but in any individual patient it's very dicey. To use $20 \%$ is just one more misapplication of that silly rule.

Busse: Ron Sorkness evaluated ${ }^{1}$ the data from the SARP [Severe Asthma Research Program] network through the NIH [National Institutes of Health]. 
He has determined RV in patients with asthma. In patients with more severe disease there is an increase in RV and air trapping. Whether it reflects airway parenchyma and coupling or not is not clear, but it might tell you something about the disease and the lung functions associated with severe asthma. Air trapping is associated with increased risk for exacerbations.

1. Sorkness RL, Bleecker ER, Busse WW, Calhoun WJ, Castro M, Chung KF, et al; Heart, Lung, and Blood Institute Severe Asthma Research Program. Lung function in adults with severe but stable asthma: air trapping and incomplete reversal of obstruction with bronchodilation. J Appl Physiol 2008;104(2):394-403.

MacIntyre: A comment and then a question. The comment is that one of the things I find useful about lung volume measurements is in helping interpret the diffusing capacity. Specifically, what I'm interested in is how closely the single-breath measurement of lung volume (ie, alveolar volume) is to what we think is the real lung volume.

As you pointed out quite nicely, in obstructive lung disease those 2 things are often quite disparate, and when I see that on a diffusing capacity test, where alveolar volume is like $50 \%$ of the known TLC, I put up a big red flag and say, "I'm not sure you can interpret that $\mathrm{D}_{\mathrm{LCO}}$, because the gases obviously didn't mix very well." If the methane or the xenon or whatever you happen to be using as your tracer gas didn't mix, I guarantee you the CO didn't mix either. I don't know any way to fix that other than to say diffusing capacity is probably very difficult if not impossible to interpret.

A question I have that comes up all the time is the pattern of a patient who has a flat out normal VC but a $70 \%$ TLC. A lot of people try and tell me that means restriction, and I have a lot of trouble thinking about that physiologically because it would mean that the restrictive process is attacking the $\mathrm{RV}$ and leaving the $\mathrm{VC}$ alone. I, for one, can't think of a disease process that preferentially goes only after RV. Maybe I' $m$ missing something, but I'd appreciate somebody's comments there.

Hnatiuk: During my fellowship training, one of the staff informed me that early interstitial lung disease could present with a decrease in the residual volume before other lung volumes were affected. Now, I've never gone back and looked for data that myself-

MacIntyre: Wait, before I let you off the hook here, I've looked for this, and the reading I've done suggests that early interstitial lung disease makes the lung stiff. As the lung gets stiff, you tend to lose VC first and the RV may trail behind it. So maybe after this conference we can finally find some literature to help us answer this question.

Culver: I can comment on that, but I don't have a lot of data. Because RV beyond a 35 or 40 is mostly a function of airway closure, if you do have increased recoil, then you have delayed airway closure and you can get to a lower RV, and so it's rational that an interstitial process could be associated with that.

MacIntyre: Did you just describe a larger RV? I'm sorry; did I misunderstand?

Culver: No, there's more recoil, so the airways are less inclined to close. They go to a lower volume before they close and cause RV to be low. That pattern has been described, more particularly in sarcoidosis for some reason, which seems a little curious, because that often has an airway component as well, but I recall there was a small series years ago that showed that pattern in sarcoid patients.

Ruppel: The reference that I showed from Piotr Boros ${ }^{1}$ in which they looked at ILD [interstitial lung disease] con- cluded that the TLC was reduced more than the vital capacity in ILD patients, which suggests that the RV may be changing.

1. Boros PW, Franczuk M, Wesolowski S. Value of spirometry in detecting volume restriction in interstitial lung disease patients. Respiration 2004;71(4):374-379.

Enright: A common problem is that the reference equations (predicted values) and the lower limits for FVC and for the TLC are taken from 2 entirely different studies. The lower limits may not have been appropriately analyzed in one or both of those studies. That could cause the difference. Reference values for spirometry and lung volumes should come from the same population-based study.

Coates: What is going on in a lot of pediatric labs may be very different from adult labs, but despite the standards suggesting the frequency of panting should be at $1 \mathrm{~Hz}$, I frequently find them panting at 2,3, or $4 \mathrm{~Hz}$. No matter how many times we tell the technicians, they and the patient both find it easier to pant at a much higher rate. That is going to introduce errors into the measurements, and those errors may well be the explanation as to why there is this discrepancy between dilutional techniques and plethysmographic techniques. It is possible that the plethysmographic techniques just were not done the right way.

Ruppel: The O'Donnell paper that I discussed ${ }^{1}$ didn't go into great detail, but they suggested each of their techniques (helium dilution, CT scanning, and plethysmography) followed the current guidelines.

1. O’Donnell CR, Bankier AA, Stielbellehner L, Reilly JJ. Comparison of plethysmographic and helium dilution lung volumes: which is best in COPD? Chest 2010;137(5): 1108-1115.

Coates: We try to insist in our lab that we follow the current guidelines, 
but as soon as I walk out the door, I often can hear rapid panting.

Miller: Paul once again raised a critical issue. If you look at your own lab reports and at the predicted FVC versus the predicted VC, you'll see markedly different predicted values. This lack of concordance between reference values raises the question of what does the TLC really mean. One thing we've tried to do is take the RV/TLC or VC/ TLC ratio from your lung volume predicteds and apply it to the FVC from your spirometric predicteds and generate a new RV and TLC from that. Statistically, the spirometry predicteds are much better, they' re based on many more individuals who are better defined as normal, so I think that's a useful approach.

I'd like to bring up this question of losing out to the radiologists again, and I think that's really going to happen for reporting lung volume and diagnosing emphysema, because when you look at your patients, especially in the teaching centers, they're all getting CTs. It is available to the radiologist to report many things, emphysema score, percentage of lung volume with emphysema, TLC, and so on. They don't do it because nobody's interested, but very few of your patients whom you're considering as having severe emphysema or ILD escape getting a CT scan.

The last question I'd like to ask is something I get asked by my fellows all the time and I don't know how to answer. When you have something reducing your ERV, and of course obesity does this very readily, and there isn't necessarily a proportional change in FRC. So if obesity or some other condition like patient testing variability is giving you a low ERV and you're measuring a more or less normal FRC, then you're going to have to have a high RV. And what does that high RV mean in the presence of a low ERV? Does anybody have any suggestions there? I see you're nodding, Paul.
Enright: What is the definition of hyperinflation? A high RV, a high RV/ TLC, a high FRC, a high FRC/TLC, or a high trapped air volume? Which of those is best correlated with the airway obstruction in asthma or COPD, and which of those is the most responsive to interventions? Our ATS/ ERS committee never addressed those definitions, and it leads to continued confusion in the literature.

Kaminsky: The issue of the discrepancy you've talked about, I've always been puzzled by that as well. Why in obese patients do we see the relatively high RV to TLC? Are they really gas trapping and so it has to do with early airway closure? Or one thing I've always wondered is whether it's more of a mechanical effect, that is, since it's an effort-dependent maneuver, these patients just can't squeeze down to lung emptying as they would otherwise be able to do if they weren't obese. But I don't know the answer to that.

Pichurko: As a pulmonary fellow I was introduced to RV as a volume that is either "dynamically determined," that is, representing roughly the point of predominant airway closure and residual gas trapping, or "staticallydetermined," as in disorders that reduce chest wall compliance and limit the "ride down" the respiratory system's static pressure-volume curve. Obesity, absent concurrent airway disease, is a common prototype of the statically determined elevated RV that is well above the airway closing volume. Neuromuscular weakness is another.

Hnatiuk: In our lab, when you get a low FVC, a normal TLC, and a normal RV/TLC ratio. the question becomes, "What is going on?" This leads us to look at the maximum inspiratory pressure and maximum expiratory pressure. If they are normal, then we attribute the low FVC to submaximal patient effort during the FVC maneu- ver. But I think Gregg had a reference addressing this group of patients in his talk, who were followed longitudinally and I believe a substantial portion of them developed disease?

Ruppel: Yes, the Mayo Clinic group. ${ }^{1}$ Their patients had the nonspecific pattern, which is a little different than what we were just talking about, but yes, some of them did go on to develop restrictive disorders when they were tested sequentially. The large majority (64\%) tended to remain in the nonspecific pattern grouping, but some did go into a restrictive pattern and some went into an obstructive pattern. That was similar to what Hyatt observed in the original group. ${ }^{2}$ Obesity and subclinical obstruction seemed to be the characteristics of those patients who had that pattern.

\footnotetext{
1. Iyer VN, Schroeder DR, Parker KO, Hyatt RE, Scanlon PD. The nonspecific pulmonary function test: longitudinal follow-up and outcomes. Chest 2011;139(4):878886.

2. Hyatt RE, Cowl CT, Bjoraker JA, Scanlon PD. Conditions associated with an abnormal nonspecific pattern of pulmonary function tests. Chest 2009;135(2):419-424.
}

Hnatiuk: So is it worth it to say in the report, "repeat the spirometry in a year" and see where these people end up?

Ruppel: I think that might be the case. If you observe the nonspecific pattern, the question would be, is this patient on the path to developing restriction? Again, you have to do the lung volume measurement.

Salzman: To follow up on the issue of this nonspecific pattern and the whole interaction of obesity with asthma or mild obstructive lung disease, I think part of the problem is that we tend to interpret with thresholds, and it's a black-and-white approach: you're either normal or abnormal. The reality is that a lot of these 
things are a continuum, and we don't know how to deal with that in an individual patient.

I thought it was very interesting that you pointed out that with obesity, FVC and other lung volumes tend to migrate within the normal range, such that you end up with measurements that are still "normal," but you're near the lower limit of normal. I think the same thing happens with mild obstructive lung disease, the $\mathrm{FEV}_{1}$ and the
$\mathrm{FEV}_{1} / \mathrm{FVC}$ ratio are in that area just north of lower limit of normal, a little north of say $80 \%$ for $\mathrm{FEV}_{1}$ or 0.70 for $\mathrm{FEV}_{1} / \mathrm{FVC}$. So when you combine obesity and asthma, two very common conditions, you end up with what the Mayo Clinic is calling the nonspecific pattern.

I think the better term that has lost out is pseudo-restriction. It's what you see a lot. I think obesity tends to cause a slightly low-normal FVC, and if we're talking about somebody who has mixed asthma and obesity, the FVC migrates downward from the obesity, the $\mathrm{FEV}_{1}$ migrates downward from the obstructive lung disease, and you end up with a normal $\mathrm{FEV}_{1} /$ FVC ratio that you can't frankly call obstruction and you don't quite know how to deal with it, it looks like borderline restriction. I think it's a very common pattern that you see in PFT labs.

This article is approved for Continuing Respiratory Care Education credit. For information and to obtain your CRCE

(free to AARC members) visit

www.RCJournal.com 